\title{
JAGE-691
}

\section{Fish Cognition and Consciousness}

\author{
Colin Allen
}

colallen@indiana.edu

phone: +1-812-606-0881

fax: $+1-812-855-3631$

Program in Cognitive Science and Department of History and Philosophy of Science Indiana University, Bloomington, IN 47405 USA

\begin{abstract}
Questions about fish consciousness and cognition are receiving increasing attention. In this paper, I explain why one must be careful to avoid drawing conclusions too hastily about this hugely diverse set of species.
\end{abstract}

Keywords. Fish, learning, cognition, consciousness

\section{Introduction to the controversy}

The cognitive and mental capacities of fish are a current topic of scientific controversy, and consciousness is the most contentious of topics. In a recent review article, Michel Cabanac and coauthors (Cabanac et al. 2009) argue that consciousness did not emerge until the early Amniota, the group of species that includes mammals, birds, and "reptiles." The latter term is in scare quotes because biologists consider it a paraphyletic group (i.e., a group that contains just a subset of the descendants of its common ancestor) that is improper for classification purposes due to its exclusion of the birds, which descended from the saurians. Amniotes are characterized by an embryonic membrane that makes terrestrial reproduction feasible. The amphibians, lacking this adaptation, are constrained to place their eggs in an aqueous environment for proper development. These biological details are important because of the nature of some of the evidence that Cabanac et al. bring to bear on the question of consciousness in fish - evidence that I shall maintain seems skewed towards other adaptations that have to do with terrestrial life.

But before getting into those details, it is important to recognize that Cabanac's is not a consensus view. For instance, in her book Do Fish Feel Pain? Victoria Braithwaite argues that "there is as much evidence that fish feel pain and suffer as there is for birds and mammals" (2010). What is this evidence? Braithwaite and her colleagues have pursued a number of interesting experiments over the years subject- 
ing fish (typically trout) to a variety of noxious stimuli (e.g., injection of bee venom into their lips) and then measuring various behavioral changes. Rainbow trout that received the bee venom treatment spent considerably more time over the next few hours, rubbing their lips on the bottom and sides of their tanks (Sneddon et al. 2003). Similarly they showed an increased gill rate, indicating higher respiration, and reduced feeding behavior (even when starved), less attention to novel objects placed in the tank, and amelioration of all of these symptoms by morphine. All of these establish behavioral and physiological effects similar to those found in mammals, where it is largely a matter of scientific (if not philosophical) consensus that there's no adequate basis for denying conscious pain experiences to them.

As I shall discuss in greater detail below, the controversy over fish reasserts itself in the domain of neuroanatomy. Rose (2002) argues that fish nociception (i.e., sensory receptiveness to harmful stimuli) occurs without consciousness. Cabanac et al. (2009) argue circumstantially (albeit somewhat circumspectly) that the massive expansion of cortical tissue in the amniotes provides further evidence to support the division they propose. Their circumspection comes with reference to Merker's (2007) paper on consciousness without a cerebral cortex, and their admission that there's no solid evidence to locate emotional and affective aspects of consciousness entirely within cortical tissue. Cabanac et al. also maintain that the expression of endogenous opioids in amniotes far exceeds that in amphibians and the various fish species. I will return to the neuroanatomical and neurophysiological issues later in the paper. It is worth noting here, too, that the category of "fish" provides another example of a paraphyletic group, so not a strictly recognized biological category. Furthermore it is an incredibly diverse group of organisms, accounting for more than $60 \%$ of the known vertebrate species. For these reasons, and more to be explained below, it is important to be cautious filling in the blank for any generalization that begins "Fish do ___ or "Fish have ."

Why should philosophers care about fish consciousness? Of course, philosophers of science are attracted to scientific controversy - perhaps like gawkers at a road accident, albeit with dreams of performing a heroic rescue! - and some of this attitude will be evident throughout this paper. But what about other philosophers? For practical (or applied) philosophy, especially ethics, the issue is obvious. Many selfdescribed "vegetarians" consider fish to be fair game for their dinner plates. Fish cultivation is perhaps the most rapidly expanding part of animal agriculture, and already governments are scrambling to devise appropriate regulations, and the agriculture industry is striving to know more about what makes fish healthy and perhaps happy. Furthermore, fish are increasingly finding a place in scientific laboratories as model systems for research into a wide range of genetic, neurological, and behavioral functions and dysfunctions. The practical and ethical concerns are evident, for example, in the research of Braithwaite and others who come out of so called "animal welfare science" - a branch of science has its roots in animal hus- 
bandry and veterinary medicine. Despite the ethical significance of this work, I shall not have anything specific to say about the ethics of eating or cultivating fish in this paper.

For "theoretical philosophy," as I will argue below, fish provide an interesting test of the boundaries of existing conceptions of cognition and consciousness. In addition, as I will also argue, the recent flurry of studies on fish provides some salutary lessons for the philosopher of cognitive science or animal behavior, helping us understand the limits of experimentation in these areas. For general philosophy, there is also an element of "Know thyself!" although fish are sufficiently alien that the reflection is sometimes hard to discern. (Curiously, in the "Great Chain of Being" - e.g., Didacus Valades 1579 depiction - fish have been depicted as below birds and above terrestrial animals; air and water being nobler elements than earth. Proximity to divinity has not always been a straightforward matter of physical resemblance to man.)

In the remainder of this paper, then, I will be demonstrating that there are jobs for philosophers here. Many of the scientists participating in these debates have turned to philosophers for definitions of concepts such as emotion and consciousness. Sometimes they have not handled what they have found in ways that philosophers would approve. See, for example, Gary Varner's (2011) review of Braithwaite (2010) where he maintains that she confuses feelings with complex thoughts, and gets carried away with the notion of access consciousness (Block 1995) -- the availability of information in part of the system for global reasoning processes -- which Varner says is irrelevant to what really matters ethically, namely "phenomenal consciousness" -- i.e., the subjective "what it is like" aspect of conscious experience. Here I disagree slightly with Varner. Although some philosophers define phenomenal consciousness independently of access consciousness, this doesn't mean that they aren't as a matter of fact functionally relevant to each other (see below). However, I don't disagree either in general or specifics that scientists sometimes misunderstand and therefore abuse philosophical distinctions. In addition to the work of conceptual clarification (if not outright definition), philosophers of science bring a keen eye to certain staples of this debate, such as the use of arguments from analogy, inference to the best explanation, and frustration with the skeptical problem of other minds. Elsewhere I have argued that we have strategies for dealing with all of these, strategies that I shall illustrate below in the context of discussion of fish consciousness. Philosophers may also sometimes be in the lucky position of being able to take in the big picture, assimilate ideas from a variety of fields, take a long view of the different roles played by various kinds of empirical studies on our understanding of possible forms of consciousness other than our own.

\section{The limits of definition}


Michel Cabanac (pers. comm.) emphasizes the importance of definitions in enabling scientific communication. But definitions are negotiable. Cabanac et al. (2009) begin their paper with a reference to Bering and Borklund (2005) who define consciousness as "a higher-order cognitive system enabling access to intentional state." Philosophers will associate such a definition with the work of Peter Carruthers (2000). However, Cabanac et al. don't mean "higher-order" in the same way that Carruthers and certain other higher order theorists do, that is in terms of explicit mental representation of first-order intentional states - thinking about thoughts. Rather, they speak in terms of processing of information through a "single mental space" (Cabanac et al. 2009, p.267) with sensory pleasure and displeasure providing the common currency for decision making by which the deliverances of different perceptual systems could be weighed against each other. (In Carruthers' scheme, this is all realizable without higher-order thought.) Regardless of the merits or demerits of their conception, it helps us understand what Cabanac's experiments are intended to support - namely the idea of pleasure or pain as the main currency for a "single mental space." But it requires perhaps further argument to say that this is the right conception; or, better than an argument would be to establish through a long-term empirical research program that the definition is empirically productive and unifies several phenomena.

The philosophical literature standardly makes several distinctions among meanings of consciousness. This is not the place to review them all, but for discussions of animal consciousness, five seem especially salient, with two of them proving most controversial (Allen 2010). These include the distinction between sleeping and waking states, perceptual awareness and sensitivity, access consciousness, phenomenal consciousness, and self-awareness.

The awake/asleep distinction is not usually in dispute when applied to mammals, although there has been controversy about whether fish sleep (Cabanac et al. 2009). The sense of consciousness implicated in the basic ability of organisms to perceive and thereby respond to selected features of their environments is not under dispute (the sense in which a minnow can be aware of a predator), although its relevance to more controversial notions is disputed. The more technical notion of access consciousness was introduced by Block (1995) to capture the sense in which mental representations may be poised for use in rational control of action or speech. This "dispositional" aspect of consciousness, in which information content is available for other systems to use, although perhaps not currently being so used, is amended by Block (2005) to include an occurrent aspect in which the content is actively "broadcast" in a "global workspace" (Baars 1997), which is how it comes to be available for higher cognitive processing tasks such as categorization, reasoning, planning, and voluntary direction of attention. Block believes that many animals possess access consciousness (speech is not a requirement) although it's not clear what he thinks about fish. 
The idea of a global workspace is perhaps close enough to the idea of "single mental space" to make this a plausible interpretation of Cabanac's conception, but for the fact that Cabanac et al. add the additional dimensions of feeling and/or emotion to the story. In this way they move closer to the philosophers sense of phenomenal consciousness -- the qualitative, subjective, experiential, or phenomenological aspects of conscious experience, sometimes identified with qualia. To contemplate animal consciousness in this sense is to consider the possibility that, in Nagel's (1974) phrase, there might be "something it is like" to be a member of another species.

Finally, self-consciousness refers to an organism's capacity for second-order representation of the organism's own mental states. Because of its second-order character ("thought about thought") the capacity for self consciousness is closely related to questions about "theory of mind" in nonhuman animals whether any animals are capable of attributing mental states to others. Although questions about selfconsciousness and theory of mind in animals are a matter of active scientific controversy, I am not aware of any scientific studies about self-consciousness in fish - however, Desjardins and Fernald (2010) detected a measurable difference in brain activity (via activity of marker genes) between a male cichlids challenging another male and one challenging its own mirror image.

I shall have nothing else to say about self-consciousness in this paper, but all the other notions remain on the table for discussion.

\section{Are fish robotic?}

The idea that fish behavior might be entirely accounted for as fixed responses to specific stimuli leads some to suggest that fish are robots, relatively simple Stimulus-Response (S-R) machines driven in an inflexible way by current inputs. This view of fish as living entirely in the present is also manifested in the common myth that goldfish (Carrassius aureatus) have a 3-second memory span. This myth has been busted several times, most recently in August 2008 by an Australian 15-yr old schoolboy's science fair project in a story that got wide press coverage, although the American television show MythBusters did it earlier (Season 2 Episode 11; January 25, 2004; http://mythbustersresults.com/episode11) for a previous debunking. These (admittedly not peer-reviewed) experiments show that goldfish retain the effects of training for months. Of course, even taking the experiments at face value, they do not prove either flexible cognition or conscious memory of past experiences because the kind of behavioral conditioning that produces these lasting behavioral changes can happen at an entirely unconscious level in human beings, and simple S-R models are precisely concerned with such learning.

A debate is currently active among comparative psychologists about whether evidence from experiments on various animals - especially, e.g., rats (Babb and Crystal 2006; Zhou and Crystal 2009), and 
birds (Clayton and Dickinson 1998; Clayton et al. 2006) - establish that they have more flexible forms of episodic memory, i.e., memories for specific events that can be deployed in circumstances not anticipated at the time of the experience. Some in the human literature (e.g., Tulving and Markowitsch 1998) have wanted to link episodic memories specifically to self-awareness (or "mental time travel," in Tulving's words). Interestingly, in the neuroscience community, it is simply taken for granted that the experimentalists' methods tap into episodic memory in rats, and work is done on the underlying mechanisms (e.g., Eichenbaum et al. 2012). Nevertheless, regardless of one's willingness to call it "episodic memory," or more conservatively "episodic-like memory," there is now very credible evidence that rats and jays can use information gained in single experiences to act appropriately given new information that was not available at the time of the original experience.

To my knowledge, no one has yet systematically investigated whether fish of any species possess episodic memory. But there are reports of one-trial learning - single experiences leading to adaptive changes in behavior. For example, Arai et al. (2007) report that a observation of a predator attack is sufficient to produce changes in the behavior of Japanese flounder Paralichthys olivaceus towards predators. And Schuster et al. (2006) showing that archerfish Toxotes jaculatrix, who use their gills to force jets of water through their mouths to knock insects into the water, can learn to hit moving targets accurately by repeatedly observing others do it, without having to practice the skill themselves. What mechanism could account for this is presently unknown.

The diminished reputation of fish for being rather unsophisticated learners can perhaps be traced to a widely-cited paper by Bitterman (1975), who demonstrated a difference between the performance of 3 goldfish and 2 rhesus monkeys in a reward matching task. When given a choice between two responses, one of which was rewarded $70 \%$ of the times it was selected and the other $30 \%$, the goldfish "matched" by randomly selecting the $70 \%$ target $70 \%$ of the time, for an average return rate of $58 \%$ (= $(.7 x .7)+(.3 x .3))$ as measured over the course of 10 days of trials. The two monkeys, in contrast, approached $100 \%$ response to the $70 \%$ target after 10200 -trial blocks of training. This higher rate of return is arguably more "rational" insofar as the monkeys maximized their reward rate in these circumstances.

Experimentation on goldfish as proxies for all fish is also evident in the work of Cabanac, already mentioned. Cabanac and Laberge (1998) investigated the response of six goldfish to two treatments (and a control). In the two treatment conditions, the fish were handled and injected with either a saline solution or pyrogens (fever-inducing bacteria). The fish were then placed in a pair of connected tanks, one at 37C and the other at $34 \mathrm{C}$. After being injected with the pyrogens, the fish spent significantly more time in the cooler tank than during the unhandled control condition or saline-injected condition. Cabanac et al. argue that the fact that the saline-injected fish do not prefer the cooler tank shows that fish, in contrast to amniotes, do not have "emotional fever" - an increase of body temperature after events that might be ex- 
pected to cause an emotional response, such as the handling involved in receiving an injection. I shall return to Cabanac's bigger conclusion that fish therefore lack emotions below, but for now the point is just that a small sample of goldfish is used to draw conclusions about all fish.

\section{Unconscious but not asleep?}

In their 2009 review article, Cabanac and colleagues also suggest that the lack of play behavior and REM sleep in fish (and amphibians) further indicates a bright line can be drawn at the amniotes. The case of sleep is an interesting one. From an evolutionary perspective, it is usually considered that sleep is the harder state to explain. After all, sleeping animals are vulnerable to predation, and potentially missing feeding and reproductive opportunities. Of course, this is somewhat simplistic because daytime feeders may not have been able to find food at night, and they run the risk of being preyed upon by nocturnal specialists; and vice versa. Nevertheless, a $24 \mathrm{hr}$ cycle of activity and quiescence seems to be evolutionarily ancient and it is beyond doubt that many species of fish are less active during one phase of the day than during the other.

Cabanac et al. (2009) argue, citing Nicolau et al. (2000), that the phenomenon of awakening depended on the evolution of brain cortex, and they restrict their definition of sleep to slow wave cortical activity. As far as I can tell, the argument by Cabanac et al. is not based on a direct investigation of any species of fish, but on a somewhat circular definition derived from the neural characteristics of the sleep/wake cycle in mammals. Fish don't have cortices, so they don't have slow wave activity in their cortices. But Nicolau et al. actually undermine this argument by claiming that despite the lack of cortex patterns, slowwaves patterns in sub-cortical structures may be indicators of sleep. They go on to argue that something homologous to rapid eye movement (REM) sleep is likely in reptiles.

The insistence by Cabanac on REM sleep is quite telling. The evolution of eye movement control in fish has followed a rather different trajectory than that in mammals. (For one thing, many fish species have independent eye movements that are bilaterally controlled, so it's far from clear why a particular pattern of eye movements during sleep should be replicated at all in such a system.) No doubt REM movement seems significant because it is associated in humans with dreaming, and we observe it in other mammals. But it is quite hard to know whether REM sleep is connected to dreaming in, say, dogs, even though it is tempting to interpret other simultaneous motor activity as (e.g.) the dog dreaming it is running. This, however, is sheer speculation, and the cognitive significance of sleep is hard to assess, although sleep-deprived animals suffer impairments in learning (e.g., Graves et al. 2003; but see Cai et al. 2009 for dissent), show various physiological changes, and suffer a rebound effect - needing to catch up on missed sleep - once the circumstances preventing sleep are removed. It is thus concluded that sleep 
serves a biological need in similar to water, food, and other basic needs that must be caught up with after a period of deprivation.

The idea that fish have somehow never (in evolutionary time, or their life times) woken up is, on the face of it absurd. Sleeping animals don't learn, don't eat, and even during rare episodes of human sleepwalking show none of the reactive behavioral capacities that most fish display. But lest this become a mere terminological dispute, more specificity about a functional characterization of sleep is needed. Such work is sparse, but Yokogawa et al. (2007) have looked at physiological and behavioral aspects of the sleep state in zebrafish Danio rerio, comparing a wild type to a specific genetic mutant. They show that sleep deprivation in these fish also produces a rebound effect. They characterize sleep in terms of different thresholds for arousal, with the sleep state having a higher threshold for arousal. By comparing the two genetic types, Yokogawa et al. (2007) localized a part of the regulatory mechanism to the anterior hypothalamic area, and they argue that the findings from the genetic mutants suggest "molecular diversity in sleep regulatory networks across vertebrates." But is it REM sleep? (A question posed to me by Cabanac when he heard about this.) Of course not, if REM sleep is defined by a particular pattern of neocortical activity, which is important to processes of memory consolidation in humans and perhaps other mammals. But to define sleep in terms of neocortical patterns, or to insist that only REM sleep is relevant to whether fish can be conscious in the sense of "not asleep," is to prejudge an empirical question by mammalian anatomy. Convergent evolution may implement similar functions in structures that are not homologous.

Sleeping fish should not be ruled out by definition, because functional convergence across different biological taxa should not be ruled out a priori. Indeed this raises an important point about taxonomic diversity. Just as there are different patterns of sleep across the mammals, one should expect there to be at least as much taxonomic diversity among fish. (In fact more, as the next section explains.) For the same sorts of reasons that porpoises (like migratory birds) have been found to sleep one half of their brains at a time, one might expect fish to show similar diversity between reef dwellers and the pelagic inhabitants of the open oceans.

\section{From goldfish to fish}

Thus far I have followed many authors in using "fish" generically as if this is a biologically appropriate category for making broad cognitive comparisons. In fact, it is something of a folk category (albeit a slightly scientifically-modulated category - for example insofar as it no longer contains whales and dolphins). Nevertheless, the group of organisms we intuitively call "fish" comprises several taxonomic groups and huge number of species - approaching 32,000 currently, and given the rate of discoveries es- 
timated to asymptote somewhere near 35,000 . As such, these species account for around $60 \%$ of all vertebrate species. Taxonomic classifications are currently undergoing enormous revisions, and fish are not excluded from this upheaval, so anything written in this paragraph could already be out of date by the time it is read. Nevertheless, several major divisions are recognized at the time of writing. These include the jawless fish (lampreys and hagfish), and the Gnathostomata, or jawed fish (the latter a paraphyletic group). The jawed fish include cartilaginous fish (sharks, rays, and "ghost sharks), the ray-finned fish (comprising the nearly 95\% of all known species, including the Teleosts, or "bony" fish that make up the majority of the forms most familiar at fishmongers, pet shops, and touristic snorkeling spots), and the "lobe-finned" or "fleshy-finned" fish. This latter group includes the "living fossil" Coelacanth, the lung fishes, and is the lineage that gave rise to all the land vertebrates. This makes the latter group paraphyletic, since some of its descendants (including ourselves) are not classified as lobe-finned fish. The lobefinned fish separated from the ray-finned over 400 million years ago, whereas the Teleosts do not appear in the fossil record until the Triassic period, between 250 and 200 million years ago. It is perhaps edifying to remind ourselves that tuna are more closely related to us than they are to sharks, and that coelacanths are more closely related to us than they are to tuna. (Thanks to Michael Trestman, pers. comm., for offering this succinct summary of the points about phylogeny.)

The enormous radiation of fishes has led to tremendous diversity among them. Contrary to popular opinion, not all fish are ectothermic, or "cold-blooded." Some sharks and several teleosts (e.g., some species of tuna and swordfish) are partial or complete endotherms. Swordfish can raise brain (including eye) temperatures, while tuna maintain overall body temperatures well above ambient water temperatures. Sensory mechanisms are also diverse, and include modalities not familiar to humans. For example, many fish rely on their lateral line organs to sense changes in water pressure, and in some species these have been modified into electroreceptors capable of sensing electromagnetic fluctuations in the $1 \mathrm{KHz}$ range. The so-called "weakly electric" fish have also been measured to produce such fluctuations at the same rate, which is believed to have a communicative function (Zhou and Smith 2006).

The mating and reproductive systems of fish are also extremely diverse. Most fish species are egg layers (oviparous), but some hold the eggs internally until they hatch (ovoviviparous) and some even have a proto-placental arrangement to support the developing embryos (viviparous). The diversity of these arrangements is also mirrored in the varieties of parental care (or lack thereof) shown towards hatchlings. Male seahorses are famous for the fact that it is the fathers who protect eggs and hatchlings. Mate fidelity is present in some species, but by no means all, and sometimes such "monogamy" is socially- or environmentally-regulated (Whiteman and Côte 2004). Some species of fish are sequential hermaphrodites, starting life as females but becoming male if they survive to become the largest member of their group. 
Given such enormous diversity, one must be very careful when speaking about "fish" generically, and even more cautious about drawing conclusions about all fish, based on experiments conducted with just a few representatives of one species. Goldfish may be convenient and cheap to use in experiments, but at best representative only of closely-related species, and maybe not even fully representative of their own species if raised in artificial conditions. Irrespective of the question of representativeness, the fact that the thermoregulatory responses of an aquatic ectotherm ("cold-blooded") species are different from those of terrestrial vertebrates is of questionable use for a strong argument. The common ancestor of the Amniotes and the Teleost fish was neither and amniote nor a teleost, and the modern fish are separated by hundreds of millions of years of independent and very significant evolution from that common ancestor. The significant changes that have occurred are often masked by the hydrodynamic demands of swimming in water, such that to our untrained eyes, most fish look rather similar over vast evolutionary differences.

\section{From brainstem to telencephalon}

Some of the arguments about fish capacities have been predicated on neural differences between fish brains and mammal brains. For example, Rose (2002) states:

The fundamental neural requirements for pain and suffering are now known. Fishes lack the most important of these required neural structures [extensive frontal and parietal neocortical regions], and they have no alternative neural systems for producing the pain experience. Therefore, the reactions of fishes to noxious stimuli are nociceptive and without conscious awareness of pain.

To say that these mammalian structures are required for pain is, of course, to beg an important question. Even if neocortical structures are required for mammalian pain experiences, it does not follow that they are required for fish. There are issues concerning convergent evolution and multiple realizability of mental capacities here, and the neuroscience cannot stand alone. Behavioral and physiological measures are essential too, if the neuroscientific evidence is to be interpreted correctly.

The telencephalon (forebrain) of fish (any species) is a poorly understood structure whose function is not well understood. Neuroscientist Klaus-Peter Hoffman, who has conducted single-cell recording in fish brains (Masseck and Hoffman 2008) reports that it is very hard to find evidence of electrical activity in the telencephalon, and neuron counts appear low in that structure, although he admits this may be an artifact of the staining methods used (pers. comm.). In comparison, the fish midbrain (mesencephalon) is much developed, especially in teleost fish, and there is considerable variation among different species. 


\section{From learning to cognition}

With those caveats out of the way, what is known about the cognitive capacities of various fish species? The answer is more than before, but still not much. Recent studies have documented that that groupers Plectropomus pessuliferus and moray eels Gymnothorax javanicus engage in extended bouts of cooperative hunting (Bshary et al. 2006) and data have been presented to argue that cleaner wrasses Labroides bicolor are more likely to take a chunk out of clients they are less likely to encounter again (Oates et al. 2010). The capacity of mosquitofish Gambusia holbrooki to estimate the number of individuals in a group has been studied (Dadda et al. 2009), as have the tool-using abilities of stingrays Potamotrygon castexi (Kuba et al. 2010 ). Like comparative studies of animal cognition in general, some of this work tends towards what I have elsewhere called "trophy hunting" (Allen, forthcoming). Nevertheless, it underscores the point that "fish" should not be dismissed as cognitively uninteresting en masse.

The observational learning in archerfish discussed above is not an isolated instance of social learning (reviewed by Brown and Laland 2003). Such studies should make us wonder about the robustness of Bitterman's (1975) results, reported to show that goldfish have a less optimal form of learning than monkeys, since there was likely considerable differences between the fish and the monkeys in the opportunities for learning and social interaction, and well as other potentially significant experiences, before they entered Bitterman's experiment. The point is underscored by a more recent experiment involving cichlid fish of the species Simochromis pleurospilus showing that the ability of adults to learn was affected by whether or not the individuals experienced a single change in feeding regime during the first nine months of their lives. Fish that were maintained on a constant low quantity diet or constant high diet did worse a year later on a learning test than fish that had experienced a switch either from low to high or high to low once

during the developmental period (Kotrschal and Taborsky 2010). This study illustrates the importance of experience during development for cognition (see also Stotz and Allen 2011), and should make us worry about the importance of unreported and uncontrolled differences in the handling and thus the experiences of different species in comparative experiments such as Bitterman's.

\section{From cognition to consciousness}

So, we have before us an array of evidence for greater cognitive and learning sophistication among a handful of fish species, militating against any blanket conclusions covering the entire paraphyletic group. But what does this tell us about consciousness in the sense that excites concerns about the ethical treatment of fish? It depends, of course, on one's preferred theory of "phenomenal consciousness." I will not 
attempt a thorough survey here (see Allen 2010). Rather, I focus on my own view (Allen 2004; Allen et al. 2005; Allen et al. 2009) which takes certain kinds of learning to be better indicators of consciousness than others because they connect theoretically to accounts of phenomenal consciousness that emphasize the role of "appearance states" (roughly, how things seem to the animal) in enabling flexible error correction and information integration from multiple sources over various timescales. This is how, as mentioned above, phenomenal consciousness may be related to access consciousness, for access to how things appear can be important to learning. For instance, Clark and Squire (1998) showed that in human subjects, "delay conditioning," in which a learned response to a conditioned stimulus (CS) that overlaps temporally with another that already produces the response (the US, for "unconditioned stimulus") can occur without any explicit knowledge of the relationship. In contrast, "trace conditioning," which requires retention of a memory trace in working memory for pairing with a later stimulus, is perfectly correlated with subjects learning about the relationship between two stimuli and their ability to report verbally on that relationship; those subjects who were unable to report on the relationship were exactly those who failed to acquire the response to the CS. It is suggestive in this context that Clark and Squire showed that rabbits, like humans, were $100 \%$ conditionable in a delay conditioning experiment, but similarly only about half of them learned the response in trace conditioning involving the same stimuli. Recently, trace conditioning has been investigated in a handful of species including Atlantic cod Gadus morhua (Nilsson et al. 2008), Atlantic halibut Hippoglossus hippoglossus (Nilsson et al. 2010), and rainbow trout Oncorhynchus mykiss (Nordgreen et al. 2010). Vargus et al. (2009) also suggest that one of the functions of pallial areas of fish brains is to support trace conditioning.

Full operant conditioning, in which a wide range of stimuli can be flexibly connected to a wide range of behavioral actions, is also worthy of further investigation for the light it can shed on conscious experiences. Operant conditioning involves the reinforcement of spontaneously produced behavior by subsequent events. What gets reinforced need not be a specific motor pattern, but a goal-directed response that can flexibly recruit alternative movements -- e.g., by using a different limb to execute the response if the original one is blocked. Kirsch et al. (2004) argue that it is hard to explain operant conditioning in humans without cognitive involvement involving conscious expectancies. Allen et al. (2005) also argue that the operant conditioning in place preference learning task can be used to study the dissociability of affective and sensory components of pain, thus enabling an experimental approach to assessing the different dimensions of the pain experience in animals. More specifically, an animal that has been given a moderate dose of morphine may react by pulling away from a noxious stimulus such as a mild electric shock, but show no tendency to move away from the place where the noxious stimuli are delivered (absence of place-preference conditioning). In such a system, it might be possible to disentangle the affective (bothersome) aspect of pain from its sensory (nociceptive) dimensions. However, some caution is necessary 
since some analogs of the phenomena used to argue for conscious mediation of learning have been found in the spinal cords of rats (Allen et al. 2009). Nevertheless, the forms of instrumental learning exhibited in the spinal cord are not as sophisticated as fully flexible operant conditioning. To my knowledge, there has been relatively little systematic investigation of operant conditioning in fish (but see Tennant and Bitterman 1975).

\section{Conclusions}

B.F. Skinner (1984) speculated that "it would not be hard to teach a fish to jump from a lower level to a higher one." I suspect that he was thinking of salmon and never actually tried this with any fish, particularly not a flounder. I have argued that given the diversity of fish species and the limited extent to which they have been studied, blanket statements about fish cognition and consciousness are not responsible. Previous studies that seemed to show limited capacities of certain fish in specific experiments may be due to developmental or ecological factors that were not controlled in those experiments and are perhaps as yet unimagined. Fish provide an important group of species for studying evolutionary convergence of behavior and cognition despite neurological differences. Neither a purely behavior approach nor a purely neurological approach to arguments about cognition and consciousness is tenable. The possibility of convergent evolution at the behavioral and cognitive levels despite morphological and anatomical differences at the neurological level makes fish an enormously interesting testing ground for ideas about multiple realizability of cognition

When it comes to ethical questions concerning fish welfare, standards of evidence may be different for practical philosophy versus theoretical philosophy or science. Practical ethics cannot wait for all the relevant aspects of every species of fish to be scientifically investigated, but must also be wary of the dangers of overreaching (see Allen 2006 for more elaboration of this point). Theoretical philosophers and scientists can afford to be more cautious and skeptical of claims about fish cognition and consciousness, but must also be careful to respect the limits of experimental methods. Unfortunately, the vast majority of fish species are likely to remain empirically inaccessible, perhaps forever. Nevertheless, it is encouraging to see behavioral and cognitive investigations being conducted on species such as cod and halibut that are becoming increasingly important to human agriculture.

Philosophers have much to learn and much to contribute in this fascinating area. There is work to be done linking the various capacities that are shared among members of the same species, or unique to individual organisms, to issues of ethical and general philosophical concern. It is no longer adequate for us to throw up our hands at the apparent impossibility of knowing what it is like to be a member of another species, based solely on the kind of information than one could glean from a children's encyclopedia. In- 
stead, motivated philosophers have the opportunity to help test and expand the limits of our current scientific and philosophical conceptual schemes by engaging more thoroughly with sciences, thereby coming to appreciate and help organize human understanding of the enormous behavioral, neurological, and cognitive diversity among the vast array of species lumped together under the deceptively simple label of "fish."

Acknowledgments I am grateful for comments to audiences at the University of Utrecht, the Ruhr University, Bochum, and at the Leibniz Institute for Inland Fisheries and Freshwater Ecology in Berlin, and for comments on the manuscript by Michael Trestman, Bernice Bovenkerk, members of the "Spackled" group at Indiana University, and two anonymous referees for the journal. I also gratefully acknowledge the support of the Alexander von Humboldt Foundation and Indiana University during the time that this paper was prepared, and the hospitality of the Ruhr University-Bochum during my sabbatical year.

\section{References}

Allen, C. (2004) Animal Pain. Noûs 38, 617-643.

Allen, C. (2006) Ethics and the Science of Animal Minds. Theoretical Medicine and Bioethics 27, 375394.

Allen, C. (2010). Animal Consciousness, In The Stanford Encyclopedia of Philosophy (Winter 2010 Edition), Edward N. Zalta (Ed.), http://plato.stanford.edu/archives/win2010/entries/consciousnessanimal/. Accessed May 13, 2011.

Allen, C. (forthcoming). Private Codes and Public Structures. In David McFarland, Keith Stenning, and Margaret McGonigle-Chalmers (Eds.) The Complex Mind: An Interdisciplinary Approach, London: Palgrave-Macmillan

Allen, C., Fuchs, P.N., Shriver, A. and Wilson, H. (2005) Deciphering Animal Pain In M. Aydede (Ed.) Pain: New Essays on the Nature of Pain and the Methodology of its Study. MIT Press; pp. 352-366.

Allen, C., Grau, J.W., and Meagher, M.W. (2009) The Lower Bounds of Cognition: What Do Spinal Cords Reveal? In John Bickle (Ed.) The Oxford Handbook of Philosophy of Neuroscience. Oxford University Press, 129-142.

Arai, T, Tominaga, O., Seikai, T., Masuda, R. (2007) Observational learning improves predator avoidance in hatchery-reared Japanese flounder Paralichthys olivaceus juveniles. Journal of Sea Research 58, 59-64.

Baars, B.J. (1997). In the Theatre of Consciousness: Global Workspace Theory, A Rigorous Scientific Theory of Consciousness. Journal of Consciousness Studies 4, 292-309. 
Babb, S.J. and Crystal, J.D. (2006). Episodic-like memory in the rat. Current Biology 16, 1317-1321.

Bering, J.M. and Bjorklund, D.F. (2005). The serpent's gift: evolutionary psychology and consciousness. In: Zelazo, P.D., Moscovitch, M., Thompson, E. (Eds.) Cambridge handbook of consciousness. New York: Cambridge University Press.

Bitterman, M.E. (1975) The Comparative Analysis of Learning: Are the laws of learning the same in all animals? Science 188, 699-709.

Block, N. (1995) On A Confusion About a Function of Consciousness. Behavioral and Brain Sciences 18, $227-47$

Block, N. (2005) Two Neural Correlates of Consciousness. Trends in Cognitive Sciences 9, 41-89.

Braithwaite, V. (2010) Do Fish Feel Pain? Oxford: Oxford University Press.

Brown, C. Laland, K.N. (2003) Social learning in fishes: a review. Fish and Fisheries 4, 280-288.

Cabanac, M., Cabanac, A.J., and Parent, A. (2009) The emergence of consciousness in phylogeny. Behavioral Brain Research 198, 267-272.

Cabanac M, Laberge F. (1998) Fever in goldfish is induced by pyrogens but not by handling. Physiology and Behavior 63, 377-379.

Cai, D.J., Shuman, T., Harrison, E.M., Sage, J.R., and Anagnostaras, S.G. (2009) Learning and Memory $16,595-599$.

Carruthers, P. (2000). Phenomenal Consciousness: A naturalistic theory. Cambridge: Cambridge University Press.

Clark, R.E. and Squire, L.R. (1998) Classical Conditioning and Brain Systems: The Role of Awareness. Science 280, 77-81.

Clayton, N. S. and Dickinson, A. (1998). Episodic-like memory during cache recovery by scrub jays. Nature, 395, 272-274.

Clayton, N.S., Emery, N., and Dickinson, A. (2006) The rationality of animal memory: Complex caching strategies of western scrub jays. In S. Hurley and M. Nudds (eds.) Rational Animals? Oxford University Press.

Dadda, M., Piffer, L., Agrillo, C., Bisazza, A. (2009). Spontaneous number representation in mosquitofish. Cognition 112, 343-348.

Desjardins, J.K. and Fernald, R.D. (2010) What do fish make of mirror images? Biology Letters 6, 744747.

Eichenbaum, H., Sauvage, M., Fortin, N., Robitsek, R.J., Komorovski, R. (2012). A comparative analysis of episodic memory. T.R. Zentall and E.A. Wasserman (Eds.), The Oxford Handbook of Comparative Psychology. Oxford University Press, in press 
Graves, L.A., Heller, E. A., Pack, A. I., and Abel, T. (2003) Sleep deprivation selectively impairs memory consolidation for contextual fear conditioning. Learning and Memory 10, 168-176.

Kirsch, I., Lynn, S.J., Vigorito, M., Miller, R.R. (2004) The role of cognition in classical and operant conditioning. Journal of Clinical Psychology 60, 369-392.

Kuba, M.J., Byrne, R.A., Burghardt, G.M. (2010). A new method for studying problem solving and tool use in stingrays (Potamotrygon castexi). Animal Cognition 13, 507-513.

Kotrschal, A., and Taborsky, B. (2010). Environmental Change Enhances Cognitive Abilities in Fish. PLoS Biology 8(4): e1000351. doi:10.1371/journal.pbio.1000351

Masseck, O.A. and Hoffmann, K.-P. (2008) Responses to moving visual stimuli in pretectal neurons of the small-spotted dogfish (Scyliorhinus canicula). Journal of Neurophysiology 99, 200-207.

Merker B. (2007) Consciousness without a cerebral cortex: a challenge for neuroscience and medicine. Behavioral and Brain Sciences 30, 63-81.

Nagel, T. (1974). What is it like to be a bat? Philosophical Review 83, 435-450.

Nicolau, M.C., Akaârira, M., Gamundía, A.,González, J., and Rial, R.V. (2000) Why we sleep: the evolutionary pathway to the mammalian sleep. Progress in Neurobiology 62, 379-406.

Nilsson, J., Kristiansen, T.S., Fosseidengen, J.E., Fernö, A., and van den Bos, R. (2008). Learning in cod (Gadus morhua): long trace interval retention. Animal Cognition 11, 215-22.

Nilsson, J., Kristiansen, T.S., Fosseidengen, J.E., Stien, L.H., Fernö, A., and van den Bos, R. (2010) Learning and anticipatory behaviour in a "sit-and-wait" predator: the Atlantic halibut. Behavioral Processes 83, 257-266.

Nordgreen J, Joseph P, Garner J.P., Janczak, A.M., Ranheim B, Muir W.M. and Horsberg T.E. (2009) Thermonociception in fish: Effects of two different doses of morphine on thermal threshold and posttest behaviour in goldfish (Carassius auratus). Applied Animal Behaviour Science 119, 101-107.

Nordgreen, J., Janczak, A.M., Hovland, A.L., Ranheim, B., Horsberg, T.E. (2010) Trace classical conditioning in rainbow trout (Oncorhynchus mykiss): what do they learn? Animal Cognition 13, 303-309.

Oates, J., Manica, A., Bshary, R. (2010). The shadow of the future affects cooperation in a cleaner fish. Current Biology 20: R472-R473.

Rose, J. (2002) The Neurobehavioral Nature of Fishes and the Question of Awareness and Pain. Reviews in Fisheries Science 10, 1-38.

Schuster, Stefan, Saskia Wöhl, Markus Griebsch, and Ina Klostermeier (2006) Animal Cognition: How Archer Fish Learn to Down Rapidly Moving Targets. Current Biology 16, 378-383.

Skinner, B.F. (1984) The Evolution of Behavior. Journal of the Experimental Analysis of Behavior 41, 217-221. 
Sneddon, L. U., Braithwaite, V. A. and Gentle, M. J. (2003) Do fish have nociceptors: evidence for the evolution of a vertebrate sensory system. Proceedings of the Royal Society 270, 1115-1121.

Stotz, K. and Allen, C. (2011) From cell-surface receptors to higher learning: A whole world of experience. In Kathryn S. Plaisance and Thomas A. C. Reydon (Eds.) The Philosophy of Behavioral Biology, Berlin: Springer, pp. 85-123.

Tennant, W. A. and Bitterman, M. E. (1975). Blocking and overshadowing in two species of fish. Journal of Experimental Psychology: Animal Behavior Processes 1, 22-29.

Tulving, E. and Markowitsch, H.J. (1998) Episodic and declarative memory: role of the hippocampus. Hippocampus 8, 198-204.

Vargas, J.P., López, J.C., Portavella, M. (2009) What are the functions of fish brain pallium? Brain Research Bulletin 79, 436-440.

Varner, G.L. (2011) Review of Victoria Braithwaite, Do Fish Feel Pain? (Oxford University Press, 2010). Environmental Ethics 33, 219-222.

Whiteman, E.A. and Côte, I.M. (2004) Monogamy in marine fishes. Biological Reviews 79, 351-75.

Yokogawa T, Marin W, Faraco J, Pézeron G, Appelbaum L, Zhang, J., Rosa, F., Mourrain, P., Mignot, E. (2007) Characterization of Sleep in Zebrafish and Insomnia in Hypocretin Receptor Mutants. PLoS Biology 5(10): e277. doi:10.1371/journal.pbio.0050277

Zhou, M. and Smith, G.T. (2006). Structure and sexual dimorphism of the electrocommunication signals of the weakly electric fish, Adontosternarchus devenanzii. Journal of Experimental Biology, 209, 4809-4818.

Zhou W. and Crystal, J.D. (2009). Evidence for remembering when events occurred in a rodent model of episodic memory. Proceedings of the National Academy of Sciences, 106, 9525-9529. 